\title{
Novos tempos e a emergência de uma nova classe média na periferia do capitalismo
}

\author{
Ualace Roberto de Jesus Oliveira ${ }^{1}$
}

1 Mestre em Economia pela Universidade Federal da Bahia (UFBA), Brasil. E-mail: ualacejesus@bol.com.br

RESUMO: Nas últimas duas décadas, ocorreu um importante processo de expansão da atividade econômica em escala global, e esse fato corroborou para promover a ascensão social de miIhares de indivíduos da base da pirâmide social. Esse processo no Brasil ficou conhecido por muitos autores como a emergência de uma nova classe média. Diversos fatores contribuíram para tal fato no referido país, tais como: a criação de milhares de empregos formais, a política de valorização real do salário mínimo, a popularização do consumo de bens e serviços via expansão do crédito, dentre outros fatores. Nesse ínterim, diversos autores elaboraram metodologias com o intuito de mensurar a dimensão da nova classe média mundial. Dito isso, esse trabalho tem como objetivo fazer uma discussão teórica sobre a emergência de uma nova classe média na periferia do capitalismo.

New times and the emergence of a new middle class in the periphery of capitalism ABSTRACT: In the last two decades, there has been an important process of expansion of economic activity on a global scale, and this fact corroborated to promote the social rise of thousands of individuals at the base of the social pyramid. This process in Brazil was known to many authors as the emergence of a new middle class. Several factors contributed to this fact in the country, such as the creation of thousands of formal jobs, the policy of real appreciation of the minimum wage, popularization of consumption of goods and services through credit expansion, among other factors. In the meantime, several authors have developed methodologies to measure the size of the new world middle class. That said, this paper aims to make a theoretical discussion about the emergence of a new middle class in the periphery of capitalism.

\section{INTRODUÇÃO}

O crescimento econômico dos países emergentes tem recebido muita atenção nos últimos anos. As implicações desse crescimento tem ajudado expandir as oportunidades econômicas além de transformar a paisagem política em alguns dos países mais populosos do mundo (DADUSHI; SHIMELSE, 2014) Nesses países, grupos significativos de pessoas ascenderam verticalmente na pirâmide social, ingressando assim na classe média. Nesse processo, o deslocamento da riqueza mundial da Europa para as chamadas nações periféricas mostra uma tendência histórica em que a economia global está se remodelando (SPITZCOVSKY; PEREIRA, 2012). O primeiro fator que permitiu o crescimento desse novo grupo social foi o processo de urbanização. Como consequência disso, a população urbana ultrapassou a população rural mundial pela primeira vez na história da humanidade. Associado a isso, temos o segundo fator: as reformas econômicas aplicadas nessas nações, fato que permitiu um crescimento econômico acima da média (SPITZCOVSKY; PEREIRA, 2012).

Dito isso, não foram apenas aspectos conjunturais de dado momento da história 
que tiveram importância, mas também mudanças de cunho institucional que alguns países vivenciaram nesses últimos anos. No caso do Brasil, além da sorte, nome dado a conjuntura externa favorável que contribuiu para melhorar os termos de troca dos produtos brasileiros no comércio internacional, está também a virtú que consistiu na adoção de políticas macroeconômicas importantes, como o tripé macroeconômico: meta de inflação, câmbio flutuante, superávit primário. Tais questões, inclusive, ajudaram a criar um ambiente institucional que corroborou para gerar expectativas positivas no empresariado de modo a favorecer a ampliação de investimentos produtivos. Vale ressaltar que muitos aspectos relacionados ao mercado de trabalho melhoraram significativamente, haja vista a economia crescer a patamares mais elevados e com maior regularidade nos últimos anos. Esse conjunto de transformações alterou profundamente as percepções e estratégias de ascensão social, cujo horizonte deixa de ser apenas pessoal e se torna coletivo. Assim, milhões de brasileiros experimentaram um importante processo de mobilidade social em um contexto de mudança no plano das identidades coletivas (LAMOUNIER; SOUZA, 2009).

Este artigo tem como objetivo, por meio de uma abordagem descritiva, fazer uma discussão teórica sobre a emergência de uma nova classe média na periferia do capitalismo. Este trabalho se justifica com o intuito de compreender o fenômeno da emergência de uma nova classe média mundial. Em termos metodológicos, o trabalho consistiu numa revisão de literatura.

\section{EMERGÊNCIA DE UMA NOVA CLASSE MÉDIA NA PERIFERIA DO CAPITALISMO}

Segundo Dadushi e Shimelse (2014) o surgimento de uma classe média global é um fenômeno real. Pela definição mais usada, há uma estimativa de 369 milhões de pessoas em países do G20 que são, atualmente, consideradas de classe média, embora esse número possa ser subestimado. Em comparação, há cerca de 1 bilhão de membros da classe média residentes em países avançados, de acordo com a definição mais utilizada. Ainda conforme o referido autor, o mundo em desenvolvimento, especialmente, é o que tem vivenciando esse processo com mais intensidade. Uma década atrás, $83 \%$ da população mundial estava vivendo em países em desenvolvimento, mas era responsável por apenas $18 \%$ do consumo privado global. Hoje, essa população é de $85 \%$ e a sua quota de consumo privado mundial saltou para quase $30 \%$. O consumo privado nos países em desenvolvimento tem vindo a crescer em cerca de três vezes a taxa dos países avançados, o que se reflete em um rápido crescimento da demanda não apenas para as necessidades, tais como o trigo, mas também para bens considerados de luxo, tais como telefones celulares e ar condicionado, por exemplo, (DADUSHI; SHIMELSE, 2014).

De acordo com MacLennan (2014), o rápido crescimento dessas e de outras economias além de estar remodelando a distribuição da renda no mundo está tornando-a significativamente mais igualitária. Ademais, as transformações econômicas raramente deixam de afetar as outras esferas da vida, e as mudanças atuais, provavelmente, não serão exceção. Uma característica dessas mudanças estará no movimento 
de um mundo com a atividade econômica altamente concentrada na América do Norte, Europa e Japão para uma economia mundial mais equilibrada, com vários mercados regionais significativos:

Além das mudanças entre os países, que começaram a reverter a "Grande Divergência" do Século XX, haverá transformações significativas no ambiente interno, na medida em que as populações mudam da pobreza para uma vida mais afluente. As demandas políticas e materiais das pessoas de classe média são muito diferentes daquelas dos ricos e pobres, com o potencial de perturbar o equilíbrio institucional em muitas nações (MACLENNAN, 2014, p.6).

Nesse processo, no centro desta massiva transformação de riqueza presente em riqueza futura está a nova classe média dos BRICS, fato que talvez seja a face humana mais palpável desta revolução (NERI et al, 2011). Os países emergentes conquistam crescente atenção mundial, especialmente depois da recente débâcle dos países ricos. Os BRICS (Brasil, Rússia, Índia, China e agora a África do Sul) seriam os principais tijolos edificadores da riqueza em 2030. E estes países que juntos abrigam mais da metade dos pobres do mundo hoje, multiplicará até 2050 por sete a sua relação com a renda gerada nos países do G7.

Em um trabalho intitulado "Mobilidade social no capitalismo e redivisão internacional da classe média", Pochmann (2013) elaborou um estudo sobre a divisão da classe média no mundo onde descreve que em 2009 havia cerca de $1 / 4$ da população do planeta na classe média considerada pelo critério exclusivamente de renda. $\mathrm{O}$ autor supramencionado destaca que 1,8 bilhões de pessoas têm rendimento médio de entre 10 a 100 dólares diários. Para o ano de 2020 projeta-se 3,2 bilhões de pessoas identificadas como sendo de classe média:

Entre 1995 e 2009 houve um aumento de $40 \%$ na expansão relativa da classe média asiática. Ainda para o mesmo conjunto de indicadores de definição de classe média global por critério de rendimento, registra-se a redivisão no total da renda compreendida pelos segmentos de rendimento intermediário (10 a 100 U\$S) (POCHMANN, 2013, p.166).

Mas, o autor ainda aponta que está ocorrendo um decréscimo na participação relativa da população de classe média, pelo critério citado acima, nos países da America do sul e central, bem como nos países da America do Norte e da Europa ${ }^{\underline{1}}$. Tal fato é fruto do processo de desindustrialização que os países dos continentes supramencionados têm enfrentado. Outrora os países da América do Norte e Europa que antes concentrava $2 / 3$ da classe média global, tornaram-se residuais na redivisão da classe média mundial, com cerca de $1 / 5$ do total das pessoas com rendimento familiar per capita entre 10 e 100 dólares (POCHMANN, 2013).

Sobre o processo declínio da classe média em países europeus Dallinger (2013) observou que esse processo em países ricos ocorreu pela primeira vez em países como EUA, Reino Unido, Austrália, Canadá e Nova

\footnotetext{
${ }^{1}$ Nos últimos anos, um debate público começou sobre o encolhimento da classe média em vários países europeus. O aumento das disparidades na distribuição de renda é vista como perigo para a classe média. Assim, o medo é que ele não será apenas os grupos de baixa renda, que serão confrontados com o agravamento das perspectivas de emprego e oportunidades de renda. Então, um debate que começou muito mais cedo nos países de língua Inglês liberais devido a um aumento das desigualdades, que começou a ser observado na década de 1970 já atingiu a Europa continental.
} 
Zelândia. Nesses países, o debate sobre esse o assunto ocorreu cedo, haja vista o aumento geral das disparidade de renda a partir dos anos 1970 provocado pelo neoliberalismo (DALINGER, 2013). Segundo o autor, a maioria dos países europeus experimentaram esse problema mais tarde, pelo fato de possuir regulamentos mais abrangentes do mercado de trabalho, além de negociação salarial coletiva e programas de assistência social que ajudaram a retardar os efeitos nefastos da desregulamentação. Mas a partir do momento em que a desigualdade começou a aumentar na Europa se passou a estudar o aumento da pobreza e as consequências da desregulamentação sobre emprego remunerado e na distribuição de renda. Como observa Dalinger (2013), a desregulamentação afeta particularmente grupos com baixas qualificações e com fraco poder de barganha sindical. Outrora a desregulamentação e a pobreza eram tidas como um perigo que apenas as classes menos afortunadas enfrentariam, e por isso tais questões não eram percebidos como risco para as classes médias. Hoje, no entanto, se reconhece que países como a França e Alemanha mesmo tendo economias de mercado bem coordenadas e com estado de bem-estar corporativo as classes médias estão ameaçadas (DALINGER, 2013).

Sobre o debate concernente à emergência de classes médias no continente asiático, Rougier (2015) destaca que a expansão do referido grupo está associada à expansão do consumo e o investimento em capital humano. No que tange a expansão do consumo tem grande importância a expansão de uma classe de funcionários localizados nos níveis médios da escala de renda e capaz de consumir bens de industrialização mais diversificados. Ademais, por ter um peso demográfico mais elevado do que os grupos de renda mais alta, a classe média pode criar oportunidades de mercado e economias de escala para as empresas nacionais (MURPHY et al, 1989 apud ROUGIER, 2015).

\begin{abstract}
O acesso das classes superiores ao consumo de novos bens reduz progressivamente os preços e aumenta consequentemente $o$ acesso ao mercado de classes médias, consideradas inferiores. Simultaneamente, a diminuição mais rápida do preço de um bem, assim que as classes de renda intermediária passam a consumi-lo, libera os recursos orçamentários para as classes de rendimento superior que podem, assim, consumir novos produtos e permitir o início do desenvolvimento de um novo setor. Se o tamanho da classe média é muito limitado ou se essa classe média não é muito diferente da classe de rendimento superior, tem-se então que o desenvolvimento de uma produção diferenciada é interrompida e a economia mantém as características dualistas, com os mais ricos consumindo bens de luxo importados e os mais pobres consumindo produtos de primeira necessidade (MATSUYANA, 2002 apud ROUGIER, 2015, p. 37).
\end{abstract}

Ainda segundo Rougier (2015), a emergência de uma classe média pode igualmente influenciar as mudanças econômicas através do investimento em capital humano. De acordo com os autores, o fato das famílias pobres se tornarem de classe média deveria reduzir a poupança de precaução e aumentar a capacidade de poupança global da economia.

Mas, o que caracteriza a poupança das classes médias reside provavelmente mais na sua utilização do que em seu nível. Os modelos de "armadilha da pobreza" têm mostrado que as desigualdades de acesso ao financiamento afetam as escolhas ocupacionais e os investimentos em capital humano das famí- 
lias dos países em desenvolvimento, condenam os mais pobres à ociosidade ou a empregos muito pouco produtivos (ROUGIER, $\underline{2015, \text { p.37) }}$

Desse modo, a forte propensão a poupar das famílias asiáticas poderia permiti-las ultrapassar essas restrições com fortes efeitos positivos sobre a dinâmica agregada da economia, em termos de produtividade e de transformação setorial.

Sobre a temática da nova classe média na America Latina, em um relatório elaborado pelo Banco Mundial intitulado "Economic mobility and the rise of the Latin American middle class", Lopez-Calva et al (2013) apontaram que nesse continente a classe média cresceu de forma substancial, passando de 100 milhões de pessoas em 2000 para cerca de 150 milhões no final da última década. De acordo com os autores do referido relatório, durante o mesmo período, enquanto a renda familiar cresceu e a desigualdade diminuiu na maioria dos países o percentual de pobres caiu de forma significativa de $44 \%$ para $30 \%$ :

Como resultado, as parcelas representativas da classe média e dos pobres na população latino-americana agora são quase iguais. Esses indicadores apresentam um evidente contraste com a situação que prevaleceu (por um longo período) até cerca de 10 anos atrás, quando o percentual de pobres flutuou em torno de 2,5 vezes o da classe média (LOPEZCALVA et al, 2013, p.1).

Segundo o referido estudo, pelo menos $40 \%$ das famílias da região ascenderam em termos de classe socioeconômica entre 1995 e 2010. Ou seja, 50 milhões de latinoamericanos escaparam da pobreza durante a década. Porém, o relatório aponta que:
A maioria dos pobres que prosperou não ingressou diretamente na classe média, mas passou a fazer parte de um grupo inserido entre os pobres e a classe média, que o relatório chama de segmento vulnerável e que agora constitui a mais ampla camada social na região (LOPEZ-CALVA et al, 2013, p.5).

Os membros desse grupo vulnerável, que representam 38\% da população, apresentaram um melhor desempenho em termos de renda do que os pobres, mas carecem da segurança econômica da classe média. A classe vulnerável ganha entre US\$4 e US10 per capita por dia (BANCO MUNDIAL, 2012). De acordo com Galassi e Gonzalez (2010) o termo vulnerabilidade econômica e social na América Latina é bastante recente e os estudos sobre vulnerabilidade social ganhou importância em meados dos anos 1990 como uma resposta para o desenvolvimento técnico em relação às novas formas de desigualdade social derivada da instabilidade econômica dos países em desenvolvimento e o avanço da globalização. Ainda segundo os autores supramencionados a abordagem da vulnerabilidade está cercada de uma série de novas abordagens multidimensionais dinâmicas. Além de seu valor teórico, a abordagem concernente à vulnerabilidade social é importante na agenda política, pois o risco que as famílias têm em cair na pobreza, uma vez saído dela, faz com que os governos adotem políticas sociais para puxar as famílias da pobreza, que, embora possa produzir resultados a curto prazo, não terão efeito no longo prazo (GALASSI; GONZALEZ, 2015).

Segundo o Banco Mundial (2012) durante décadas, a redução da pobreza ${ }^{2}$ e o cres-

\footnotetext{
${ }^{2}$ Nesse processo dois eventos tiveram papel fundamental para expansão da classe média e redução da pobreza: renda mais elevada e menor desigualdade. No en- 
cimento da classe média na América Latina e no Caribe (ALC) avançaram em ritmo muito lento porque o baixo crescimento e a persistente desigualdade detiveram o progresso. Nos últimos dez anos, no entanto, a renda apresentou uma significativa melhora na região devido a mudanças nas políticas governamentais que enfatizaram a criação de programas sociais e a estabilidade econômica:

O resultado final foi que a classe média cresceu $50 \%$ e tornou-se $30 \%$ por cento da população da região em 2009. Entre os países com melhor desempenho estão o Brasil, que compreendeu cerca de $40 \%$ do crescimento de classe média na região; a Colômbia, onde $54 \%$ das pessoas melhoraram sua situação econômica no período de 1992 a 2008; e o México, que viu $17 \%$ da sua população ingressar na classe média entre 2000 e 2010. Hoje, a classe média e os pobres na América Latina respondem por cerca da mesma parcela da população, segundo o relatório (BANCO MUNDIAL, 2012, p. 01)

O estudo elaborado pelo Banco Mundial sobre classes econômicas na América Latina concluiu que alguns dos principais fatores que favoreceram a mobilidade na América Latina foram: os aumentos dos níveis de escolaridade entre os trabalhadores, o aumento do emprego formal, a urbanização, aumento da participação das mulheres na força de trabalho e diminuição no tamanho médio das famílias. O relatório definiu a classe média em termos da renda como um segmento de indivíduos que ganham entre US\$10 e US\$50 por dia. Esse nível de ren-

tanto, em termos estatísticos, o crescimento econômico (aumento da renda média per capita) desempenhou um papel muito maior e foi responsável por $66 \%$ da redução da pobreza e por $74 \%$ do crescimento da classe média nos anos 2000 (LOPEZ-CALVA et al, 2013). dimento proporciona um aumento da capacidade de resistência a eventos inesperados e reflete uma menor probabilidade de retorno à pobreza (BANCO MUNDIAL, 2012).

Porém, o relatório também constata que, com exceção dos anos de escolaridade, a mobilidade intergeracional permanece limitada, visto que a situação econômica e social dos pais de uma pessoa jovem ainda desempenha um papel importante na determinação do seu futuro econômico.

O debate concernente à ascensão social proveniente do crescimento econômico que atingiu com mais intensidade a periferia do capitalismo é importante e precisa ser mais aprofundado. Por esta razão, faz-se necessário observar outras metodologias e novos critérios de estratificação econômica.

\subsection{Novas metodologias no estudo das classes médias}

Nos tempos hodiernos, entre as muitas possibilidades de se interpretar a dinâmica social procurar entendê-la ipse literis pelas teorias sociais do passado XIX, tornou-se anacrônico. "As categorias e os conceitos que todos nós nos acostumamos a usar, para pensar um mundo que transforma tão rapidamente, não o explicam mais" (SOUZA, 2010, p.19). Assim, o conceito de classe média passa a ter grande relevância nesse processo. Mensurar a classe média, no entanto, não é tarefa fácil, pois não existe uma definição amplamente aceita do que a constitui e as medidas baseadas na renda comumente usados sofrem de uma série de deficiências (DADUSHI; SHIMELSE, 2014)

Deve-se destacar também que a classe média é uma classificação social ambígua. Kharas (2010) aponta que é um novo consumismo que define a classe média. Ou se- 
ja, a constante extrapolação das normas de estilo de vida; a difusão de consumo conspícuos, bens de status e da concorrência pela aquisição das mesmas; e a crescente desconexão entre os desejos dos consumidores e dos rendimentos (KHARAS, 2010).

Diante do que foi exposto, no debate sobre estratificação social a renda é considerado o critério de analise mais importante para definir classes econômicas. Assim, a identificação estatística da classe média, por exemplo, é feita com base na renda onde é estipulada uma faixa de renda na qual as famílias estão situadas (GUERRA et al, 2007). Esse critério, definido como abordagem relativa, defini a classe média como a população que está no meio da distribuição de renda da pirâmide social de um país (ROUGIER, 2015). Dito isso, segundo Birdisal (2012), uma família pode ser considerada como sendo de classe média em um país quando está situada, literalmente, no meio da distribuição de renda, ou seja, quando auferem renda per capita na faixa de $75 \%$ e $125 \%$ da média familiar. Essa abordagem permite comparar o tamanho da classe média em todos os países e dentro dos países ao longo do tempo.

Deve-se apontar que uma das grandes questões que está em evidência sobre o tema da classe média é saber até que ponto uma definição de classe média, conforme a renda, aplicada a países desenvolvidos pode ser útil a países pobres ou em desenvolvimento (SALATA, 2012). Assim, autores como Ravallion, utilizam duas definições de classe média: a classe média do mundo em desenvolvimento e a classe média ocidental:

Fariam parte da primeira aqueles que não são considerados pobres de acordo com os pa- drões medianos do mundo em desenvolvimento, mas que ainda assim são pobres quando vistos através dos padrões dos países desenvolvidos. Aqueles que não podem ser considerados pobres segundo nenhum dos dois padrões se encaixariam dentro da "classe média ocidental" (RAVALLION, 2010 apud SALATA, 2012, p. 5).

Porém, de acordo com Clement e Rougier (2015), se olharmos para a escala dos países em desenvolvimento ou região geográfica, é importante definir critérios de adesão que permitem a comparação internacional. Neste caso, a chamada abordagem absoluta deve ser preferida. Segundo esse abordagem, uma dada pessoa pode ser considerada de classe média quando tem a capacidade de poder comprar em dado período uma cesta de bens expressa em termos de paridade de poder de compra $\left(\mathrm{PPC}^{-}\right)$.

Nesse processo, o Banco Mundial define como sendo de classe média o indivíduo que possui uma renda superior a US $\$ 2$ por dia ou US $\$ 60$ dólar por mês a preços norte-americanos em termos de paridade de poder de compra. Já Kharas (2010) define a classe média global pelo consumo, considerando que o indivíduo de classe média é aquele que gasta diariamente entre 10 a 100 dólares em termos de paridade de poder de compra. Ao combinar dados coletadas durante pesquisas domiciliares em projeções de crescimento em 145 países, o autor calculou o tamanho atual da classe média global estimando separadamente o tamanho da classe média para cada um dos 145 países por ele pesquisados. Para fazer

3 Em sua versão absoluta pela teoria da paridade do poder de compra, a longo prazo as taxas de câmbio convergiam para níveis que igualam preços de uma idêntica cesta de bens e serviços entre dois países. 
isso Kharas (2010) tomou a distribuição de renda a partir de pesquisas domiciliares dos países desenvolvidos e em desenvolvimento, disponíveis no Banco Mundial e a partir destes dados estimou os parâmetros de distribuição de uma curva de Lorenz. "Estes parâmetros são usados para estimar o número de pessoas que caem nas fileiras dos rendimentos que definem a classe média" (KHARAS, 2010, p.9).

Mas, o critério da abordagem absoluta é também limitado, visto que o nível de renda estipulado no referido critério embora permita a uma pessoa comprar bens de luxo, por exemplo, não é suficiente para permitir que essa mesma pessoa possa usufruir de uma fonte de alimentação regular (DADUSHI; SHIMELSE, 2014). Conforme Kharas (2010) uma família para ser considerada de classe média é aquela deve ter condições financeiras para desfrutar, por exemplo, de uma habitação estável, oportunidades educacionais, incluindo faculdade para os seus filhos, além de aposentadoria razoável e renda discricionária que pode ser gasto em atividades de lazer e plano de saúde.

Dadushi e Shimelse (2014) também criticam os métodos que objetivam mensurar as classes médias por meio da renda - seja ele na abordagem absoluta ou relativa haja vista tais métodos sofrerem de arbitrariedade, incoerência e por estarem sujeitos a uma série de problemas de medição:

Em primeiro lugar, eles são baseados em pesquisas domiciliares realizadas com pouca frequência que variam enormemente em qualidade e pode sofrer de vários tipos de erros e distorções, incluindo o fato de que as famílias mais abastadas podem, por muitas razões querer subestimar sua renda, enquanto as famílias mais pobres podem exagerar.
(Muitas famílias também pode ser capaz de calcular sua renda.) Em segundo lugar, a renda, mesmo quando medido adequadamente, não refletem diretamente o consumo privado." (DADUSHI; SHIMELSE, 2014, p. 3).

Além disso, segundo o referido autor, a parcela de tributação e gastos do governo no PIB varia muito, e as famílias de diferentes países e em diferentes níveis de renda apresentam comportamento de poupança muito diferente.

\section{A EMERGÊNCIA DA NOVA CLASSE MÉDIA BRASILEIRA}

A discussão recente sobre a possível ascensão de uma nova classe média no Brasil é bastante oportuna e deve ser incentivada, principalmente por causa das mudanças sociais ocorridas no país nestes últimos tempos, em especial entre 2003 e 2010.

Fazendo uma retrospectiva histórica acerca das transformações sociais ocorridas recentemente no Brasil, Pochmann (2012) destaca que o país conviveu com três dimensões diferenciadas de transformação social em apenas em 50 anos, indo de 1960 a 2010. O primeiro deles ocorreu de 1960 a 1980 , onde houve no país uma forte expansão do ritmo de crescimento da renda per capita, com crescimento anual de $4,6 \%$ ao ano. Mesmo havendo essa melhora a participação do rendimento de trabalho na renda nacional caiu $11,7 \%$, o grau de desigualdade na distribuição pessoal da renda do trabalho aumentou algo em torno de $22 \%$ no período supracitado (POCHMANN, 2012).

No segundo momento houve um processo onde as condições sociais não foram favoráveis para o conjunto dos trabalhadores. 
De 1981 a 2003 o quadro geral observado foi demarcado pela estagnação do rendimento do conjunto dos ocupados, com variação anual positiva de somente $0,2 \%$ (POCHMANN, 2012). "A situação geral do trabalho regrediu consideravelmente (-14\%), tendo em vista a elevação do desemprego aberto e a proliferação de postos de trabalho de reduzida remuneração e alta informalidade contratual" (POCHMANN, 2012, p.14). A partir de 2004, conforme o autor se verifica a manifestação de uma "terceira onda" de mudanças sociais. "De maneira geral, constata-se que entre $2004 \mathrm{e}$ 2010, a renda per capita dos brasileiros cresceu a uma média anual de 3,3\%, ao passo que o índice da situação geral do trabalho cresceu em média 5,5 ao ano" (POCHMANN, 2012, p.16).

De acordo com Lamounier e Souza (2009) há outros fatos importantes nesse processo que somam com o que foram descritos acima. Em primeiro lugar, está a mobilidade da população nos gradientes de renda, visto que se tem observado o aumento da parcela da população acima do teto da pobreza (os $50 \%$ mais pobres) e abaixo do piso da riqueza (os $10 \%$ mais ricos). "Essa parcela, que aufere a renda média da sociedade, cresceu 22,8\% entre 2004 e 2008, em larga medida pelo aumento de empregos formais e pelo concomitante aumento da renda (LAMOUNIER; SOUZA, 2009, p.165). Em segundo lugar, está o aumento do potencial de consumo e, por fim, a queda significativa da desigualdade de renda. No Brasil, a desigualdade de renda apresentou tendência ascendente até 1989, quando atingiu o ponto máximo, tendo aí início um período de queda quase ininterrupta. "De meados dos anos 1990 até os dias atuais, o coeficiente de $\mathrm{Gini}^{4}$ contabilizou queda acumulada de 5,7\%, atingindo seu nível mais baixo nos últimos 30 anos" (LAMOUNIER; SOUZA, 2009, p.166).

Vale destacar que o recente crescimento da economia mundial, com destaque para o crescimento da China, beneficiou sobremaneira a economia brasileira nesse processo. O boom das commodities, como ficou conhecida a melhoria dos termos de troca dos produtos primários do Brasil no mercado internacional, permitiu ao país não apenas obter superávits comerciais, mais também acumular um expressivo montante de reservas em dólares, bem como implementar uma série de programas sociais, fato que contribuiu para o processo de emergência de um novo grupo social denominado de nova classe média.

Nesse processo, o grande aumento na renda das classes $C$ e $D$ causados pelo aumento real do salário mínimo, aposentadorias e proteção social melhoraram e muito a distribuição de renda no país. O mercado de baixa renda que outrora concentrava seu consumo em bens de primeira necessidade passou apresentar grande potencial de consumo (AZEVEDO; MARGEDAN JUNIOR, 2009). Associado a este fato, deve destacar que nos últimos anos o Brasil tem registrado um vigoroso processo de avanço das políticas de trabalho, emprego e renda fato que tem reverberado em geração de mais empregos e expansão da cobertura da proteção social (BRASIL, 2013). Desde 2004 a redução da desigualdade foi acompanhada

\footnotetext{
${ }^{4}$ O Coeficiente de Gini é uma medida de desigualdade que varia entre 0 e 1 , onde 0 corresponde à completa igualdade (no caso do rendimento, por exemplo, toda a população recebe o mesmo salário) e 1 corresponde à completa desigualdade (onde uma pessoa recebe todo o rendimento e as demais nada recebem).
} 
da volta do crescimento da economia e da aceleração de novos empregos com carteira assinada. A fonte de renda que mais cresceu nesse processo foi a de programas sociais, como bolsa-família. A seguir veio a parcela da previdência, vinculada ao salário mínimo (NERI, 2012). Em 2008, o Brasil sobreviveu razoavelmente ao primeiro impacto da crise por uma combinação de política fiscal e financeira, embora mantendo em larga medida a política monetária restritiva. Ao lado disso, sustentou as políticas sociais através de aumento real de salário mínimo, incremento do Bolsa-Família, desoneração do IPI de automóveis e de bens de consumo popular, com efeito igualmente expansivo sobre a economia.

\section{CONSIDERAÇÕES FINAIS}

É no contexto de prosperidade econômica vivenciada pelo capitalismo nas últimas décadas que emergiu, principalmente na periferia do capitalismo, um novo grupo social que tem sido chamado por muitos especialistas de nova classe média. Tal grupo que outrora não possuía representatividade social e política alguma, passou a ser percebida na sociedade a partir de então, principalmente pela mídia publicitária, como um grande mercado consumidor de bens e serviços. No Brasil, o processo de emergência desse novo grupo social ocorreu em razão da adoção deliberada de políticas sociais que foram implementadas pela maioria política que assumiu a condução do país. Porém, não há possibilidade de mensurar a real dimensão dessa nova classe média mundial, sendo que o seu tamanho varia conforme a metodologia adotada por cada estudioso do tema. Apesar das divergências entre diversas metodologias para definir a classe média, o fenômeno dos emergentes ou da nova classe média é importante e real.

\section{REFERÊNCIAS}

AZEVEDO, M. R.; MARGEDAN JUNIOR, E. O consumidor de baixa renda. São Paulo: Elsevier, 2009.

BANCO MUNDIAL. Novo relatório do Banco Mundial mostra um aumento de $50 \%$ na classe média da América e do Caribe na última década. 2012. Disponível em: <http: //www.worldbank.org/pt/news/press-relea se/2012/11/13/new-world-bank-report-find s-fifty-percent-increase-middle-class-latin-a merica-over-last-decade>. Acesso em: 14 maio 2015.

BIDIRSAL, N. Economists in confused search for the middle class in the developing worId, 2012. Disponível em: <http://www.cgde v.org/blog/oops-economists-confused-sear ch-middle-class-developing-world $>$. Acesso em: 29 abr. 2016.

BRASIL. Presidência da República. Secretária de Assuntos Estratégicos, 2013. Vozes da classe média. Disponível em: <http://www. sae.gov.br/wp-content/uploads/Revista-Vo zes-da-Classe-M\%C3\%A9dia-Novembro-201 2.pd f>. Acesso em: 10 nov. 2014.

CLEMENT, M; ROUGIER, É. Classes moyennes et émergence en asie de l'est: Mesures et enjeux. De Boeck Supérieur. Mondes en Développement, Paris, v. 1, n. 169, p. 3145, 2015.

DADUSHI, U; SHIMELSE, A. In search of the global middle class a new Index, 2014. Disponível em: <http://carnegieendowment.or g/2012/07/23/in-search-of-global-middle-cl ass-new-index>. Acesso em: 20 fev. 2015.

DALINGER, $U$. The endangered middle class? A comparative analysis of the role 
played by income redistribution. Journal of European Social Policy, v. 23, n. 1, p. 83101, 2013.

GALASSI, G. L; GONZÁLEZ, L. M. Vulnerability Factors in the Middle Class: Evidence for Argentina and Mexico after the Crisis of the 1990s. Factores de vulnerabilidad de la clase media: Evidencias para Argentina y México luego de las crisis de los años noventa. Frontera Norte, v. 24 , n. 47 , p. $89-$ 116, jan./jun. 2012.

GUERRA, A. et al. Trabalhadores urbanos ocupação e queda na renda. São Paulo: Cortez, 2007. 143 p.

KHARAS, $\mathrm{H}$. The emerging middle class in developing countries. OECD Development centre, 2010. Disponível em: <http://www. oecd.org/dev/44457738.pdf>. Acesso em: 12 mar. 2015.

LAMOUNIER, B; SOUZA, A. A classe média brasileira ambições, valores e projetos de sociedade. Rio de Janeiro: Elsevier, 2009.

LOPEZ-CALVA, L. F. et al. Economic mobility and the rise of the Latin American middle class. Washington, DC.: World Bank, 2013. MACLENNAN, M. Uma universalidade complexa: a furtividade do conceito de classe média. Porvety in Infocus, Brasília, n. 26, p. 03-06, 2014.

NERI, M. C. A nova classe média o lado brilhante da base da pirâmide. Rio de Janeiro: Saraiva, 2012. 312 p.

NERI, M. C. et al. Os emergentes dos emergentes: reflexões globais e ações globais para a nova classe média brasileira. Rio de Janeiro: FGV/CPS, 2011. $101 \mathrm{p}$.

POCHMANN, M. Nova classe média? 0 trabalho na base social da pirâmide. São Paulo: Boitempo, 2012.

POCHMANN, M. Mobilidade social no capitalismo e redivisão internacional da classe média. Heinrich Böll, 2013. Disponível em:
$<$ https://br.boell.org/sites/default/files/nc mlivrohbs.pdf>. Acesso em: 12 fev. 2015. ROUGIER, U. The endangered middle class? A comparative analysis of the role played by income redistribution. Journal of European Social Policy, 2015. Disponível em: <https: www.unitrier.de/fileadmin/fb4/prof/sOz/S ZP/Dallinger_2013_The_endangered_middl e_class_JESP_23_1.pdf>. Acesso em: 13 ago. 2015.

SALATA, A. Notas sobre a tese da nova classe média brasileira. 2012. Disponível em: <http://www.observatoriodasmetropo les.net/download/texto_andr e_salata_clas se_media.pdf>. Acesso em: 10 jan.2016.

SOUZA, J. Os batalhadores brasileiros. Nova classe média ou nova classe trabalhadora. Belo Horizonte: UFMG, 2010.

SPITZCOVSKY, J; PEREIRA, B. A nova e a veIha classe média global. Notas de sala de aula, 2012. Disponível em: <http://casadosa ber.com.br/sp/media/mediauploader//a/n/ anovaeavelhaclassemediaglobal_aula1.pdf> . Acesso em: 12 nov. 2015.

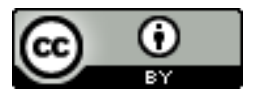

License information: This is an openaccess article distributed under the terms of the Creative Commons Attribution License, which permits unrestricted use, distribution, and reproduction in any medium, provided the original work is properly cited.

Artigo recebido em 09 de julho de 2016.

Avaliado em 09 de janeiro de 2017.

Aceito em 18 de janeiro de 2017.

Publicado em 28 de março de 2017.

Como citar este artigo (ABNT):

OLIVEIRA, Ualace Roberto de Jesus. Novos tempos e a emergência de uma nova classe média na periferia do capitalismo. Estação Científica (UNIFAP), Macapá, v. 6, n. 3, p. 63-73, set./dez. 2016. 